Pesq. Vet. Bras. 37(2):115-120, fevereiro 2017 DOI: 10.1590/S0100-736X2017000200004

\title{
Relação entre adiposidade, perfil energético, proteínas inflamatórias e lesões osteoarticulares em equinos jovens sobre diferentes sistemas de criação ${ }^{1}$
}

\author{
Lorena A. Amaral2*, Millie Marchiori², Bruna S. Moraes², Ilusca Finger², Rodrigo S. \\ dos Santos ${ }^{2}$ e Carlos Eduardo W. Nogueira ${ }^{3}$
}

\begin{abstract}
Amaral L.A., Marchiori M., Moraes B.S., Finger I., Dos Santos R.S. \& Nogueira C.E.W. 2017. [Relationship between adiposity, energy profile, inflammatory proteins and osteoarticular lesions in young horses on different rearing systems.] Relação entre adiposidade, perfil energético, proteínas inflamatórias e lesões osteoarticulares em equinos jovens sobre diferentes sistemas de criação. Pesquisa Veterinária Brasileira 37(2):115-120. Departamento de Clinicas, Faculdade de Veterinária, Universidade Federal de Pelotas, Campus Universitário s/n, Pelotas, RS 96010-900, Brazil. E-mail: lo1amaral@gmail.com

High carbohydrate diets are increasingly used in horse rearing systems. This can result in weight gain and fat accumulation in young horses. There is a growing incidence of juvenile osteoarthritis and other inflammatory conditions in overweight young horses that undergo intense physical exercise. The aim of this study was to associate corporal adiposity with energy profile, serum concentration of acute phase proteins and presence of osteo-articular lesion in the tarsal region of young horses raised in two different rearing systems: intensive system and extensive system. We evaluated 40 young horses 18 months old, 23 of them were females and 17 were males. Twenty horses were raised in the extensive rearing system and twenty horses were raised in intensive rearing system. Blood samples were collected for biochemical analysis and protein electrophoresis. Fat deposition on the crest of the neck, peritoneum and tailhead was measured by ultrasonography. Radiographic examination of the left tarsus was performed in 17 horses of the farm rearing system and in nine horses of the extensive rearing system. We observed higher levels of total cholesterol, LDL, glucose, serum amyloid A (SAA), transferrin, haptoglobin, acid glycoprotein and unidentified protein $23 \mathrm{Kda}$ in horses of the intensive system. These horses also showed higher fat deposition on the crest of the neck, peritoneum and tailhead than horses raised on extensive system. All horses on the intensive system group that underwent radiographic examination had lesions compatible with juvenile osteoarthritis while only $23 \%$ of the animals of the extensive system group showed such changes. With Fisher's exact test we observed that horses of the intensive rearing system are $105 \%$ more likely to develop osteoarthritis than horses of the extensive rearing system. With the Pearson correlation test we found a positive correlation between fat deposition on the crest of the neck and degree of articular injury. Fat deposition on the crest of the neck also showed a positive correlation with serum levels of LDL, glucose, acid glycoprotein, haptoglobin, transferrin and SAA. The SAA correlated with the thickness of retroperitoneal fat. There was a positive correlation between retroperitoneal fat deposition and presence of osteoarticular abnormalities. In conclusion, fat deposition on the crest of the neck has a correlation with energetic profile changes, cute phase proteins changes and with articular injuries. Levels of glucose, LDL cholesterol, acid glycoprotein, haptoglobin, ceruloplasmin, transferrin and
\end{abstract}

\footnotetext{
${ }^{1}$ Recebido em 9 de julho de 2015.

Aceito para publicação em 22 de agosto de 2016.

${ }^{2}$ Pós-Graduandos em Medicina Veterinária, Faculdade de Veterinária, Universidade Federal de Pelotas (UFPel), Campus Universitário s/n, Pe-
} 
SAA have a correlation with fat deposition on the crest of the neck. In addition, young horses of the intensive rearing system are $105 \%$ more likely to have chronic degenerative joint lesions compatible with juvenile osteoarthritis than horses of the extensive rearing system.

INDEX TERMS: Adiposity, energy profile, inflammatory proteins, osteoarticular lesions, horses, foals, rearing systems, obesity, acute-phase protein, osteoarthritis.

RESUMO-- Os atuais sistemas de criação de equinos estão associados às dietas ricas em carboidratos que resultam em sobre peso e acúmulo de gordura em animais ainda muito jovens. Nesses animais com sobre peso submetidos exercício físico intenso há aumento na incidência de osteoartrite juvenil e outras afeç̧ões inflamatórias. 0 objetivo deste estudo foi associar a adiposidade corporal e a forma de criação de potros com o perfil energético sanguíneo, as concentrações sanguíneas de proteínas inflamatórias e lesões osteoarticulares na região társica comparando animais criados em regimes intensivo ou extensivo. Foram avaliados 40 potros com 18 meses de idade da raça crioula, 23 fêmeas e 17 machos, sendo 20 animais criados exclusivamente em sistema extensivo e 20 animais criados em sistema intensivo. Foram efetuadas coletas de sangue para avaliação bioquímica e eletroforese proteica. Foram efetuadas através de ultrassonografia a mensuração da gordura na crista do pescoço, região retroperitoneal e na base da cauda. Em 17 animais do grupo intensivo e nove animais do grupo extensivo foi efetuado o estudo radiográfico da região do tarso esquerdo. Foi observado maiores níveis de colesterol total e LDL, glicemia, Amilóide A sérica (SAA), transferrina, haptoglobina, ceruloplasmina, glicoproteína ácida e uma proteína de $23 \mathrm{Kda}$ de peso molecular (não identificada) nos animais do grupo intensivo com relação aos do grupo extensivo. 0 grupo intensivo também apresentou maior depósito de gordura na região da crista do pescoço, região retroperitoneal e base da cauda. Em 100\% dos animais do grupo intensivo foram observados lesões compatíveis com osteoartrite juvenil, enquanto que em apenas $23 \%$ dos animais do grupo extensivo apresentaram tais alterações. No teste exato de Fisher foi observado que os animais do grupo intensivo apresentaram 105\% mais chance de desenvolver osteoartrite que os animais do grupo extensivo. Ainda, no teste de Pearson foi observada correlação positiva entre a gordura na crista do pescoço com o grau de comprometimento articular dos potros. A gordura na crista do pescoço apresentou correlação positiva com as alterações osteoarticulares, com os níveis séricos de colesterol LDL, níveis séricos de glicose, níveis de glicoproteína ácida, haptoglobina, transferrina e SAA. A SAA apresentou correlação com a espessura de gordura retroperitoneal. Conclui-se que o depósito de gordura na crista do pescoço apresenta correlação com as alterações no perfil energético, inflamatório e no comprometimento osteoarticular dos animais avaliados. Os níveis de glicose, colesterol LDL, glicoproteína ácida, haptoglobina, ceruloplasmina, transferrina e SAA estiveram correlacionados ao depósito de gordura na crista do pescoço. Potros em sistema intensivo apresentam, em relação aos criados em sistema extensivo, $105 \%$ mais chance de apresentarem lesões articulares degenerativas crônicas compatíveis com osteoartrite juvenil.
TERMOS DE INDEXAÇÃO: Adiposidade, obesidade, perfil energético, proteínas inflamatórias, lesões osteoarticulares, equinos, potros, sistemas de criação, proteínas de fase aguda, osteoartrite.

\section{INTRODUÇÃO}

A pressão da indústria do cavalo sobre a criação e a profissionalização tem feito com que animais cada vez mais jovens sejam preparados para competições morfológicas, para a doma e treinamento. Da mesma forma a busca por padrões morfológicos resultou em animais jovens, com excesso de peso, confinados e submetidos a exercício físico intenso.

As dietas ricas em carboidratos ofertadas a esses animais resultam em sobre peso e acúmulo de gordura. Esse acúmulo de gordura gera um processo inflamatório crônico que afeta todo o organismo do animal incluindo as articulações, músculos, cascos, útero, testículos, fígado e pâncreas e, consequentemente, predispõe a inúmeros problemas clínico-metabólicos (Frank 2009). Os adipócitos possuem propriedades inflamatórias intrínsecas significativas igualmente sensíveis a agentes infecciosos e a sinais inflamatórios mediados por citocinas que induzem a expressão e secreção de diversas proteínas de fase aguda e mediadores da inflamação (Berg \& Scherer 2005). 0 aumento do tecido adiposo na obesidade contribui diretamente para aumento da inflamação sistêmica. As primeiras observações deste fato datam de 1985, quando foi estabelecida uma relação entre a taxa de gordura corpórea e o número de leucócitos circulantes (Berg \& Scherer 2005).

A expressão, produção e liberação de citocinas, principalmente TNF- $\alpha$, IL-1, IL-6, PAI-1, haptoglobina e leptina, encontram-se aumentadas em indivíduos obesos. Algumas exceções são a adiponectina e a IL-10 cuja produção e níveis circulantes se encontram diminuídos em indivíduos obesos (Choi et al. 2007).

0 excesso de peso associado ao exercício também apresenta uma estreita ligação com alterações musculoesqueléticas, principalmente em animais jovens, já que a maturação óssea está incompleta e existe uma menor resistência às forças de compressão. Além disso, existe a hipótese de que o aumento na adiposidade seja capaz de alterar fatores hormonais e fatores de crescimento, interferindo no metabolismo da cartilagem articular e osso subcondral (Powel et al. 2005). Além da cartilagem, a obesidade parece ter efeito sobre outros tecidos moles, como tendão e fáscia (Wearing et al. 2006).

Garcia et al. (2009) determinaram um elevado índice de osteoatrite társica juvenil em potros da raça Mangalarga e atribuíram este fato ao treinamento precoce e excessivo associado à sobrecarga mecânica da cartilagem articular imatura. Gallio et al. (2014) também observaram alterações articulares em potros crioulos 
preparados para exposições morfológicas e ainda determinaram correlação com o depósito de gordura na crista do pescoços dos animais avaliados.

Considerando o exposto anteriormente, acredita-se que o acúmulo de gordura associado a alterações nos perfis energético e inflamatório pode estar relacionado à incidência de lesões osteoarticulares em animais jovens em sistema de criação intensivo.

0 objetivo deste estudo foi associar a adiposidade corporal e a forma de criação de potros com o perfil energético sanguíneo, as concentrações sanguíneas de proteínas inflamatórias e lesões osteoarticulares no tarso comparando animais criados em regimes intensivo e extensivo.

\section{MATERIAL E MÉTODOS}

O estudo foi desenvolvido durante o outono de 2013, em duas exposições morfológicas na cidade de Pelotas/RS, nas quais os animais foram julgados quanto a sua conformação corpórea. E ainda em dois criatórios de equinos da raça Crioula localizados no município de Bagé/RS, durante o período, as temperaturas variaram de $15^{\circ}-26^{\circ} \mathrm{C}$. Foram avaliados 40 potros divididos em dois grupos: o grupo intensivo foi composto por 20 animais com 18 meses de idade, mantidos em condição de confinamento (sistema intensivo), que foram preparados para competição morfológica e que apresentavam condição corporal entre 7-8 (escala de 1-9) (Henneke et al. 1983). 0 grupo extensivo foi composto por 20 animais com 18 meses de idade, que sempre foram mantidos soltos em campo nativo, sem suplementação alimentar e que apresentavam condição corporal de 5-6 (escala de 1-9) (Henneke et al. 1983). Os animais alocados no grupo intensivo eram submetidos ao sistema de criação intensivo e tinham sua alimentação baseada em fornecimento de $1,5 \%$ de peso vivo de ração comercial balanceada composta por: $18 \%$ de proteína bruta, $12 \%$ de fibra bruta, 3,5\% de estrato etéreo, 1,2\% de cálcio e $3.500 \mathrm{Kcal} / \mathrm{kg}$. Já os animais pertencentes ao grupo extensivo estavam em manejo de criação extensiva e sua alimentação tinha base em pasto nativo da região ad libitum.

Em ambos os grupos foram efetuadas mensurações da gordura subcutânea por meio de um aparelho ultrassonográfico munido de sonda linear com frequência variando entre 5.0 a $7.5 \mathrm{MHz}$. Foram realizadas as medidas com a sonda posicionada transversalmente na região da garupa, 7,6 cm cranial e $5 \mathrm{~cm}$ lateral à base da cauda (Gentry et al. 2004). Também foi avaliada a gordura retroperitoneal com a sonda numa posição paralela a linha média ventral na porção imediatamente caudal ao apêndice xifóide, lateral à linha média (Dugdale et al. 2011). Ainda foi aferida a espessura do depósito de gordura na região da crista do pescoço por meio da identificação do ligamento nucal, o qual serviu como limite ventral da medida. A altura da crista do pescoço foi aferida na porção média do comprimento total do pescoço, estando este em posição relaxada a um ângulo de aproximadamente de $45^{\circ}$ (Carter et al. 2009).

Para identificação de possíveis alterações radiográficas indicativas de osteoartrite procedeu-se o estudo radiológico da articulação társica esquerda nas projeções dorso-plantar, latero-medial, dorsolateral-plantaromedial oblíqua, dorsomedial-plantarolateral oblíqua. 0 exame radiológico foi efetuado de forma aleatória em 17 animais do grupo intensivo e em nove animais do grupo extensivo. Para classificação do comprometimento osteoarticular, foi adotado o escore proposto por Maranhão et al. (2006), conforme o Quadro 1.

Com intuito de se verificar o perfil energético sanguíneo e as concentrações sanguíneas de proteínas inflamatórias, foram efetuadas coletas de sangue em tubo sem anticoagulante, cujas amostras foram centrifugadas a 3.000rpm e a alíquota de soro armazenada à -80C. Posteriormente foram efetuadas mensurações de SAA (Horse Serum Amyloide A, Cusabio, EUA), leptina (Elisa Kit for Equine Lipitin, Genese, Brasil) e adiponectina (Human Adiponectin Elisa Kit, Millipore, EUA) pelo método de ELISA. Análises de triglicérides, colesterol total, colesterol LDL, colesterol HDL e proteína total, utilizando-se kit comercial (Labtest ${ }^{\circledR}$, Brasil) e ácidos graxos livres (AGL) (Enzychrom free fatty Acid Assai kit, Genese, Brasil) foram realizadas por espectrofotometria. A dosagem sérica de glicose foi realizada imediatamente após a coleta por meio de equipamento portátil de dosagem por fitas reagentes (Glicosímetro Portátil- Accutrend Plus, Roche ${ }^{\circledR}$, Alemanha). Para obtenção da concentração das frações proteicas, utilizou-se eletroforese em gel de acrilaminada contendo dodecil sulfato de sódio (SDS-PAGE), conforme técnica descrita por Laemmli (1970). Após o fracionamento, o gel foi corado durante $10 \mathrm{~min}$ em solução de azul de coomassie e, em seguida, colocado em solução de ácido acético a 7\% para retirar o excesso de corante, até que as frações proteicas se apresentassem nítidas. As concentrações dessas proteínas foram determinadas em densitômetro computadorizado (Shimadzu CS 9301 - Tokio, Japão). Como referência, utilizou-se uma solução marcadora (Sigma - Saint Louis, EUA) com pesos moleculares 29.000, 45.000, 66.000, 97.400, 116.000 e 205.000 dáltons $(\mathrm{Da})$, além de proteínas purificadas 2 - albumina, IgG, haptoglobina, ceruplasmina e transferrina.

A análise dos resultados foi realizada utilizando o programa STATISTIX $^{\circledR}$ (2008). Os dados estão descritos como média \pm erro padrão da média. Para todas as comparações foi utilizado o teste $\mathrm{t}$ de Student ao nível de 5\%. 0 teste de Pearson foi realizado

\section{Quadro 1. Escores de lesões radiograficas sugestivas de} osteoartrite juvenil segundo Maranhão et al. 2006

\begin{tabular}{cl}
\hline Grau & \multicolumn{1}{c}{ Descrição } \\
\hline 0 & Nenhuma alteração radiográfica identificável \\
1 & Presença de osteófitos intra ou periarticular \\
2 & $\begin{array}{l}\text { Presença de osteófitos, estreitamento do espaço articular, } \\
\text { alterações na densidade do osso subcondral }\end{array}$ \\
3 & Presença de osteofitos, estreitamento do espaço articular, \\
& alterações da densidade subcondral. anquilose parcial \\
4 & Anquilose total
\end{tabular}

Quadro 2. Média + erro padrão da média das concentrações séricas de indicadores de metabolismo e inflamação em potros Crioulos criados em sistemas intensivo e extensivo

\begin{tabular}{lcc}
\hline Variáveis metabólicas & Intensivo (n=20) & Extensivo (n=20) \\
\hline Leptina (ng/ml) & $0,017+0,04^{\mathrm{a}}$ & $0,057+0,00^{\mathrm{a}}$ \\
AGL (mg/dl) & $10,9+3,59^{\mathrm{a}}$ & $31,7+2,84^{\mathrm{b}}$ \\
Adiponectina (ng/dl) & $359,7+100,46^{\mathrm{a}}$ & $299,9+103,57^{\mathrm{a}}$ \\
Glicemia (mg/dl) & $105,3+2,16^{\mathrm{a}}$ & $88,4+2,33^{\mathrm{b}}$ \\
Triglicerídeos (mg/dl) & $27,9+3,07^{\mathrm{a}}$ & $40+4,65^{\mathrm{b}}$ \\
Colesterol Total (mg/dl) & $141,9+5,11^{\mathrm{a}}$ & $110,5+4,45^{\mathrm{b}}$ \\
Colesterol HDL (mg/dl) & $57,4+1,46^{\mathrm{a}}$ & $54,8+1,83^{\mathrm{a}}$ \\
Colesterol LDL (mg/dl) & $78,8+4,07^{\mathrm{a}}$ & $47,7+3,76^{\mathrm{b}}$ \\
Ceruloplasmina (mg/dl) & $16,7+0,86^{\mathrm{a}}$ & $16,2+3,98^{\mathrm{a}}$ \\
Transferrina (mg/dl) & $660,1+31,22^{\mathrm{a}}$ & $414,9+39,51^{\mathrm{b}}$ \\
Albumina (mg/dl) & $3865,4+91,43^{\mathrm{a}}$ & $3590,5+108,38^{\mathrm{a}}$ \\
Antitripsina (mg/dl) & $556,6+32,47^{\mathrm{a}}$ & $614,1+12,26^{\mathrm{a}}$ \\
Haptoglobina (mg/dl) & $102,3+8,71^{\mathrm{a}}$ & $70,1+3,74^{\mathrm{b}}$ \\
Glicoproteina ác. (mg/dl) & $8,5+1,29^{\mathrm{a}}$ & $3,5+0,43^{\mathrm{b}}$ \\
23 kDa (mg/dl) & $387,5+21,97^{\mathrm{a}}$ & $348,7+23,46^{\mathrm{a}}$ \\
Amilóide A sérica (ng/ml) & $5293,9+276,54^{\mathrm{a}}$ & $4199,0+259,14^{\mathrm{b}}$
\end{tabular}

Médias seguidas de letras iguais não diferem entre si $(\mathrm{P}<0,05)$. 
Quadro 3. Espessura da gordura acumulada na crista do pescoço, região retroperitoneal e na base da cauda nos animais criados em sistema intensivo e extensivo

\begin{tabular}{|c|c|c|}
\hline Biometria adiposa & $\begin{array}{c}\text { Sistema intensivo } \\
(\mathrm{n}=20)\end{array}$ & $\begin{array}{c}\text { Sistema extensivo } \\
(\mathrm{n}=10)\end{array}$ \\
\hline Espessura de gordura Crista $(\mathrm{cm})$ & $5,96+0,18^{a}$ & $3,41+0,35^{\mathrm{b}}$ \\
\hline $\begin{array}{l}\text { Espessura de gordura } \\
\text { Abdominal }(\mathrm{cm})\end{array}$ & $8,85+1,05^{\mathrm{a}}$ & $4,12+0,57^{\mathrm{b}}$ \\
\hline Espessura de gordura Cauda $(\mathrm{cm})$ & $10,5+0,96^{a}$ & $3,7+0,62^{\mathrm{b}}$ \\
\hline
\end{tabular}

Médias seguidas de letras iguais não diferem entre si $(\mathrm{P}<0,05)$.

\section{Quadro 4. Incidência de graus radiográficos indicativos de osteoartrite nos animais criados em sistema intensivo e} extensivo

\begin{tabular}{ccc}
\hline Grau & Intensivo $(\mathrm{n}=17)$ & Extensivo $(\mathrm{n}=9)$ \\
\hline 0 & $0 \%(0 / 17)$ & $71,5 \%(5 / 9)$ \\
1 & $23,5 \%(4 / 17)$ & $28,5 \%(2 / 9)$ \\
2 & $35,3 \%(6 / 17)$ & $0 \%(0 / 9)$ \\
3 & $41,2 \%(7 / 17)$ & $0 \%(0 / 9)$ \\
4 & $0 \%(0 / 17)$ & $0 \%(0 / 9)$
\end{tabular}

para determinar possíveis correlações entre as variáveis analisadas. Para comparar incidências de osteoartrite em os dois grupos utilizou-se o teste exato de Fisher seguido de odds ratio.

\section{RESULTADOS}

No Quadro 2 estão apresentados os valores séricos de leptina, AGL, adiponectina, glicose, triglicérides, colesterol total, colesterol LDL, colesterol HDL, ceruplasmina, transferrina, haptoglobina, glicoproteína ácida, proteína desconhecida com peso molecular de 23KDa e SAA nos grupos de potros criados em sistema intensivo e extensivo.

No Quadro 3 foram demonstrados os indicadores de adiposidade através da mensuração por ultrassonografia da espessura da gordura na crista do pescoço, na região retroperitoneal e na base da cauda dos potros das duas categorias estudadas.

No Quadro 4 estão apresentados os resultados das ocorrências de osteoartrite conforme a graduação radiológica das lesões osteoarticulares descritas por Maranhão et al. (2006), nos animais criados em sistema intensivo e extensivo.

No teste exato de Fisher foi observada diferença entre a ocorrência de osteoartrite em potros criados em sistema intensivo e extensivo, ainda foi demonstrado odds ratio (OR) de 105,1 (IC 95\% 4,476 to 2463), ou seja, documentou-se cerca de 105 vezes mais possibilidade da ocorrência de osteoatrite társica em potros do sistema intensivo.

No teste de Pearson foi observada correlação positiva entre o acúmulo de gordura na crista do pescoço com o grau de comprometimento articular dos potros avaliados $(\mathrm{p}=0,0002 ; \mathrm{r}=0,72)$. 0 depósito de gordura na crista do pescoço apresentou correlação positiva com os níveis séricos de colesterol LDL ( $\mathrm{p}=0,01 ; \mathrm{r}=0,53)$, níveis séricos de glicose $(\mathrm{p}=0,0003 ; \mathrm{r}=0,71)$, níveis de glicoproteina ácida $(p=0,007 ; r=0,56)$, haptoglobina $(p=0,009 ; r=0,54)$, transferrina $(p=0,0009 ; r=0,66)$ e SAA $(p=0,005 ; r=0,58)$. Das proteínas inflamatórias avaliadas, apenas a SAA apresentou correlação com a espessura de gordura retroperitoneal $(p=0,02 ; r=0,49)$. A espessura de gordura na base da cauda não apresentou correlação com as proteínas inflamatórias.

Os níveis de colesterol LDL apresentaram correlação com o acúmulo de gordura na crista do pescoço $(\mathrm{p}=0,01$; $\mathrm{r}=0,53)$, na região retroperitoneal $(\mathrm{p}=0,03 ; \mathrm{r}=0,42)$ e na base da cauda ( $p=0,02 ; r=0,48)$.

\section{DISCUSSÃO}

Os euqinos do sistema intensivo não diferiram dos equinos do sistema extensivo nas análises de adiponectina, leptina e colesterol HDL. A leptina é uma adipocina considerada pró-inflamatória e responsável por promover a saciedade nos animais. Na obesidade suas concentrações encontram-se alteradas e nessa situação os níveis de leptina são proporcionais a taxa de gordura dos animais. Em estudo com equinos, Kearns et al. (2006) observaram que os níveis de adiponectina, foi inversamente proporcional a taxa de gordura dos animais. Esse comportamento metabólico das adipocinas é comum em quadros de síndrome metabólica, porem acredita-se que não houve diferença entre os grupos por tratarem-se de animais muito jovens e o quadro de síndrome metabólica não tenha se estabelecido.

Apesar dos níveis de leptina e adiponectina não diferirem entre os grupos, foi observada diferença nos níveis séricos de glicose, obtidos através de glicosímetro portátil, conforme descrito por (Buzzi et al. 2013). 0 grupo de animais em sistema intensivo apresentou níveis mais elevados de glicose quando comparado aos animais em sistema extensivo. Esse fato pode ser considerado como um sinalizador de risco para o futuro desenvolvimento de resistência insulínica, já que esta é caracterizada pela elevação permanente nos níveis de glicose sanguínea.

Os potros em sistema extensivo demonstraram maior mobilização lipídica, caracterizada por maiores níveis de triglicerídeos e AGL. Este fato pode estar relacionado com o período do ano no qual foram efetuadas as coletas, que correspondeu aos períodos de grande necessidade energética, o outono, quando as temperaturas já estão mais baixas e há diminuição da qualidade do pasto nativo. Segundo Mackenzie et al. (2010) as concentrações elevadas de lipídeos no sangue estão normalmente associadas com períodos de balanço energético negativo e estresse fisiológico.

$\mathrm{Na}$ avaliação das proteínas de fase aguda foi observado que o grupo de animais em sistema intensivo apresentou concentrações sanguíneas mais elevadas de haptoglobina, glicoproteína ácida, transferrina e SAA. Os adipócitos secretam proteínas de fase aguda que, direta ou indiretamente, elevam a produção e circulação de fatores relacionados com a inflamação (Bullo et al. 2003). Existem evidências demonstrando que o processo inflamatório pode ser devido à resistência à ação da insulina e outras desordens associadas à obesidade, como hiperlipidemia e síndrome metabólica (Yudkin et al. 1999). Em equinos, a elevação nos níveis sanguíneos de haptoglobina e glicoproteína ácida está descrita em situação de exercício físico (Gondin et al. 2013), laminite (Fagliari et al. 1997), cólica e pós-operatório (Fagliari et al. 2008). Seus valores ainda não haviam sido descritos relacionados ao acúmulo de gordura e o aumento nos níveis dessas proteínas pode ser conside- 
rado um sinalizador do processo inflamatório relacionado aos depósitos de gordura dos potros em sistema intensivo, visto que foi demonstrada correlação positiva entre essas proteínas e o acúmulo de gordura na crista do pescoço.

No contexto de inflamação associada à obesidade, a SAA parece promover a inflamação local e o acúmulo inapropriado de lipídeos (Berg \& Scherer 2005). Em equinos essa proteína apresenta estreita relação com processos inflamatórios e é utilizada com sucesso no estabelecimento de prognósticos na rotina clínica. Os animais mantidos em sistema intensivo apresentaram níveis superiores de SAA com relação aos potros em sistema extensivo. Em humanos tem sido demonstrado que os adipócitos expressam SAA e que existe uma proporcionalidade entre a concentração sérica dessa proteína e o índice de massa corpórea (IMC). Estudos têm determinado que a SAA, além de ser uma sinalizadora do processo inflamatório, teria a capacidade de atuar sobre células do sistema imune e induzir a expressão e liberação de uma gama de citocinas, aumentando a produção de espécies reativas de oxigênio e espécies reativas de nitrogênio (Sandri et al. 2008). Dessa forma, os animais em sistema intensivo, além de apresentarem indícios do processo inflamatório crônico, poderiam ter esse quadro potencializado pela ação da Amilóide A.

Quando avaliados os níveis de colesterol total e colesterol LDL foi observado que esses foram superiores nos potros em sistema intensivo, os quais em sua maioria apresentavam sobre peso. Frank et al. (2006), determinando marcadores metabólicos em equinos obesos com resistência insulínica e equinos normais, observaram valores de colesterol total $30 \%$ superiores nos animais obesos. Contudo, no presente experimento, apesar dos potros em sistema intensivo apresentarem valores superiores de colesterol total e LDL, conforme discutido anteriormente, eles ainda não apresentavam alterações nos níveis de leptina, adiponectina e AGL, marcadores importantes na caracterização da resistência insulínica e síndrome metabólica. Sendo assim, tais dados reforçam o fato que esses animais apresentaram fatores de risco associados à obesidade, mas ainda não desenvolveram o quadro clínico de resistência insulínica e síndrome metabólica.

Os potros em sistema intensivo apresentaram maior espessura de gordura na região retroperitoneal, na crista do pescoço e base da cauda, caracterizando maior adiposidade nesses animais. Segundo Gentry et al. (2004), a avaliação de pontos anatômicos específicos por ultrassonografia é um método bastante viável de ser utilizado, além de ser uma técnica de mensuração extremamente confiável e de baixo custo. No mesmo estudo, os autores constataram que a espessura da gordura subcutânea na base da cauda, é a medida que mais se correlaciona com as alterações no padrão corporal. Dugdale et al. (2011) aferiram, dentre outras, a espessura da gordura retroperitoneal ventral e verificaram uma forte associação entre essa medida e o aumento do peso corporal. Carter et al. (2009), correlacionaram a altura da crista do pescoço a mudanças no padrão corporal e a distúrbios metabólicos.

$\mathrm{Na}$ avaliação radiológica foram observadas alterações compatíveis com osteoartrite em 100\% (n=17) dos potros em sistema intensivo e em $23 \%(n=2)$ dos potros em sistema extensivo. Dos potros em sistema intensivo, quatro animais apresentaram lesões GI, seis animais apresentam lesões GII e sete apresentaram lesões GIII. Nos animais em sistema extensivo, dois potros apresentaram grau inicial de osteoartrite (GI). Não foram observadas lesões com característica de anquilose articular (GIV) em ambos os grupos. Conforme Sullins (2001), a osteoartrite tem tendência à anquilose, principalmente nos casos mais avançados da doença, porém a baixa frequência se justifica pelo fato de esses animais ainda serem jovens não apresentarem os quadros mais avançados da doença.

Esses índices de alterações corroboram o estudo conduzido por Maranhão et al. (2006), no qual foi observado que $96,6 \%$ dos animais avaliados apresentavam osteoartrite társica. Garcia et al. (2009) constatou que dos trinta potros Mangalarga Marchador avaliados, 25 (86,6\%) apresentaram osteoartrite társica juvenil. Gallio et al. (2014) avaliando potros de semelhante faixa etária, da raça Crioula e também preparados para exposição morfológica, determinou a ocorrência de alterações radiológicas em 79,2\% dos animais avaliados.

Sugere-se que a elevada incidência de lesões osteoarticulares observadas nos potros criados intensivamente seja consequência das dietas ricas em carboidratos e do exercício físico associado ao sobre peso. Reiterando essa hipótese, foi observada uma correlação positiva entre o acúmulo de gordura na crista do pescoço com o grau de comprometimento articular dos potros avaliados. Dado semelhante foi observado por Gallio et al. (2014), que concluíram que o fator predisponente para as lesões articulares mais observado foi a excessiva deposição de gordura, traduzida pelo aumento no escore corporal e de deposição de gordura na crista do pescoço dos animais. Consequentemente, o excesso de peso pode levar a uma sobrecarga mecânica da articulação társica que, em conjunto com exercício físico em excesso, resulta no desenvolvimento da osteoartrite társica juvenil. Dado que justifica o resultado obtido pelo teste exato de Fisher que determinou que os potros criados em sistema intensivo apresentaram 105 vezes mais chance de desenvolver osteoartrite que os animais criados em sistema extensivo.

Quando analisadas as correlações entre as variáveis avaliadas foi observada corelação positiva entre o acúmulo de gordura na crista do pescoço com o grau de comprometimento articular dos potros avaliados. 0 depósito de gordura na crista do pescoço apresentou correlação positiva com os níveis séricos de colesterol LDL, níveis séricos de glicose, níveis de glicoproteína ácida, haptoglobina, transferrina e SAA. Das proteínas inflamatórias avaliadas, apenas a SAA apresentou correlação com a espessura de gordura retroperitoneal. A espessura de gordura da base da cauda não apresentou correlação com as proteínas inflamatórias. Esses dados corroboram os resultados obtidos por Dugdale et al. (2011), pelo qual a circunferência do pescoço ou o escore da crista pode fornecer estimativas indiretas de resistência à insulina e adiposidade corporal. E ainda permitem concluir, nesse modelo experimental, que a gordura depositada na crista do pescoço pode ser um sinalizador para 
alterações no metabolismo energético, inflamatório, sendo proporcional ao grau de lesão articular em animais jovens sobre o manejo descrito.

Os níveis de colesterol LDL apresentaram correlação com o acúmulo de gordura nas três regiões avaliadas, sendo que a maior correlação foi observada entre a concentração de colesterol com a espessura da gordura na crista do pescoço. Segundo Carter et al. (2009), a adiposidade regional em cavalos, especialmente depositado ao longo da crista do pescoço, tem sido associada a estados metabólicos alterados, incluindo resistência à insulina, e um risco aumentado de laminite.

\section{CONCLUSÕES}

O depósito de gordura na crista do pescoço apresenta correlação com as alterações no perfil energético, inflamatório e no comprometimento osteoarticular dos animais avaliados em ambos os grupos.

Os níveis de glicose, colesterol LDL, glicoproteína ácida, haptoglobina, transferrina e SAA estiveram correlacionados ao depósito de gordura na crista do pescoço.

Potros em sistema intensivo apresentam, em relação aos criados em sistema extensivo, 105 vezes mais chance de apresentarem lesões articulares degenerativas crônicas compatíveis com osteoartrite juvenil, que poderão comprometer seu futuro atlético.

Agradecimentos.- À Associação Brasileira de Criadores de Cavalos Crioulos pelo financiamento dessa pesquisa além do apoio técnico junto aos proprietários e criadores.

\section{REFERÊNCIAS}

Berg A.H. \& Scherer P.E. 2005. Adipose Tissue, Inflammation, and Cardiovascular Disease. Circ. Res. 96:939-949.

Bullo M., Garcia-Lorda P., Megias I. \& Salas-Salvado J. 2003. Systemic inflammation, adipose tissue tumor necrosis factor, and leptin expression. Obesity Res. 11:525-531.

Buzzi M.S., Helayel M.J.S.A. \& Salas-Salvado J. 2013. Análise Comparativa dos níveis de glicose pelo método glicosímetro portátil e pelo método enzimático para a dosagem da glicemia em vertebrados. Inic. Cient. Univ. Federal, T0, 9:1-5.

Carter R.A., Geor R.J., Staniar W.B., Cubitt T.A. \& Harris P.A. 2009. Apparent adiposity assessed by standardised scoring systems and morphometric measurements in horses and ponies. Vet. J. 179:204-210.

Choi K.M., Ryu O.H., Lee K.W., Kim H.Y., Seo J.A., Kim S.G., Kim N.H., Choi D.S. \& Baik S.H. 2007. Serum adiponectin, interleukin-10 levels and inflammatory markers in the metabolic syndrome. Diabetes Res. Clin. Pract. 75:.235-240.

Dugdale A.H.A., Curtis G.C., Harris P.A. \& Argo M.C.G. 2011. Assessment of body fat in the pony: I. Relationships between the anatomical definition of adipose tissue, body composition and body condition. Equine Vet. J. 43:552-561.

Fagliari J.J., McClenahan D., Evanson O.A. \& Weiss D.J. 1997. Changes in plasma protein concentrations in ponies with experimentally induced alimentary laminitis. Am. J. Vet. Res. 59:1234-1237.

Fagliari J.J., Silva S.L., Silva P.C. \& Pereira G.T. 2008. Leucograma e teores plasmáticos de proteínas de fase aguda de equinos portadores de abdômen agudo e submetidos à laparotomia. Arq. Bras. Med. Vet. Zootec. 60:322-328.

Frank N., Elliott S.B., Brandt L.E. \& Keisler D.H. 2006. Physical characteristics, blood hormone concentrations, and plasma lipid concentrations in obese horses with insulin resistance. J. Am. Vet. Med. Assoc. 228:1383-1390.

Frank N. 2009. Equine metabolic syndrome. J. Equine Vet. Sci. 29:259-267.

Gallio M., Azevedo M.S., Brass K.E., De La Corte F.D. \& Lopes L.F.D. 2014. Prevalência de alterações ósseas no tarso de potros Crioulos de até vinte e seis meses de idade. Ciência Rural 44:1442-1447.

Garcia R.S., Melo U.P., Ferreira C., Toscano F.S. \& Cruz G.M. 2009. Estudo clínico e radiográfico da osteoartrite társica juvenil em potros da raça mangalarga marchador. Ciênc. Anim. Bras. 10:254-260.

Gentry L.R., Donald L., Thompso J.R., Glen T., Gentry J.R., Vecchio D., Davis K. \& Del Vecchio P. 2004. The relationship between body condition score and ultrasonic fat measurements in mares of high versus low body condition. J. Equine Vet. Sci. 24:198-203.

Gondin M.R., Foz N.S.B., Pereira M.C., Fagliari J.J., Orozco C.A.G., Angelis F.H.F., Queiroz Neto A. \& Ferraz G.C. 2013. Acute Phase Responses of 278 Different Positions of High-Goal (Elite) Polo Ponies. J. Equine Vet. Sci. 33:956-961.

Henneke D.R., Potter G.D., Krieder J.L. \& Yeates B.F. 1983. Relationship between condition score, physical measurements and body fat percentage in mares. Equine Vet. J. 15:371-372.

Kearns C.F., McKeever K.H., Roegner V., Brady S.M. \& Malinowski K. 2006. Adiponectin and leptin are related to fat mass in horses. Vet. J. 172:460465.

Laemmli U.K. 1970. Cleavage of structural proteins during the assembly of the head of bacteriophage T4. Nature 227:680-685.

Mackenzie S.A., Roher N., Boltaña S. \& Goetz F.W. 2010. Peptidoglycan, not endotoxin, is the key mediator of cytokine gene expression induced in rainbow trout macrophages by crude LPS. Mol. Immunol. 47:14501457.

Maranhão R.P.A., Palhares M.S., Melo U.P., Resende H.H.C. \& Ferreira C. 2006. Utilização de um escore na avaliação radiográfica das lesões osteoartríticas em equídeos de tração em Belo Horizonte. Arq. Bras. Med. Vet. Zootec. 58:132-134.

Powel A., Teichtahl A.J., Wluka A.E. \& Cicuttini F.M. 2005. Obesity: a preventable risk factor for large joint osteoarthritis wich may act through biomechanical factors. Brit. J. Sports Med. 39:4-5.

Sandri S., Hatanaka E., Franco A., Pedrosa A., Monteiro H. \& Campa A. 2008. Serum amyloid A induces CCL20 secretion in mononuclear cells through MAPK (p38 and ERK1/2) signaling pathways. Immunol. Lett. 121:22-26.

Sullins K. 2001. Minimally invasive laser treatment of arytenoid chondritis in 5 horses. Am. Assoc. Equine Pract. Proceedings 47:120-122.

Wearing S.C., Henning E.M., Byrne N.M., Steele J.R. \& Hills A.P. 2006. Musculoskeletal disorders associated with obesity: a biomechanical perspective. Obesity Reviews 7(3):239-250.

Yudkin J.S., Stehouwer C.D., Emeis J.J. \& Coppack S.W. 1999. C-reactive protein in healthy subjects: associations with obesity, insulin resistance, and endothelial dysfunction: a potential role for cytokines originating from adipose tissue? Arterioscler. Thromb. Vasc. Biol. 19:972-978. 